\title{
Metastasis to the Pancreas from Breast Cancer: Difficulties in Diagnosis and Controversies in Treatment
}

\author{
Stefano Amore Bonapasta ${ }^{a}$ Matteo Gregori ${ }^{a}$ Rosina Lanza ${ }^{b} \quad$ Elena Sangiorgi ${ }^{b}$ \\ Antonello Menghi ${ }^{b}$ Massimo Scarpini ${ }^{a}$ Mauro Modesti ${ }^{c}$ \\ a Department of Surgery 'Pietro Valdoni', \\ ${ }^{\mathrm{b}}$ Breast Unit, Department of Clinical Oncology, \\ 'Breast Unit, Department of Surgical Sciences, University of Rome 'Sapienza', Italy
}

\section{Key Words}

Breast cancer - Metastasis - Treatment strategies . Differential diagnosis · Pancreas

\section{Summary}

Background: Metastasis to the pancreas originating from malignant tumours is a rare event and, in the literature, we have found only 11 reported cases of solitary pancreatic metastases originating from breast cancer. Case Report: We report a case of a 51-year-old woman with primary breast cancer who developed obstructive jaundice and epigastric pain after 2 years without any symptoms. The pancreatic mass revealed by computed tomography (CT) scan and magnetic resonance imaging (MRI) was not recognised as a metastasis from breast cancer and the patient underwent cephalic pancreaticoduodenectomy. Conclusions: We discuss all aspects of the case management, stressing the importance of a careful evaluation of the clinical history and the primary cancer features and the usefulness of a multi-disciplinary approach. These aspects are of main importance for a correct diagnostic process and an appropriate therapeutic choice when a pancreatic lesion develops in a patient with prior neoplasm.

\section{Introduction}

Metastasis to the pancreas from malignant tumours is a rare event; they constitute less than $5 \%$ of all pancreatic malignancies [1]. The pancreas may be involved by direct invasion from cancers of neighbouring organs, like stom-

\author{
Schlüsselwörter \\ Brustkrebs - Metastasen - Behandlungsstrategien · \\ Differenzialdiagnose $\cdot$ Pankreas
}

\section{Zusammenfassung}

Hintergrund: Eine Metastasierung bösartiger Tumoren in das Pankreas ist ein seltenes Ereignis, und in der Literatur haben wir nur 11 Fälle von solitären Metastasen im Pankreas gefunden, die von einem Brustkrebs ausgingen. Fallbericht: Wir berichten vom Fall einer 51-jährigen Frau mit Brustkrebs, die nach 2 Jahren Symptomfreiheit eine obstruktive Hepatitis und Schmerzen im Oberbauch entwickelte. Der Pankreastumor, der mittels Computertomografie (CT) und Magnetresonanztomografie (MRT) entdeckt wurde, wurde nicht als Brustkrebsmetastase erkannt, und die Patientin wurde einer partiellen Pankreatikoduodenektomie unterzogen. Schlussfolgerungen: Wir diskutieren alle Aspekte des Fallmanagements, wobei wir die Bedeutung einer sorgfältigen Evaluierung der klinischen Vorgeschichte und der Eigenschaften des Primärtumors sowie die Nützlichkeit eines multidisziplinären Ansatzes betonen. Diese Gesichtspunkte sind von großer Bedeutung für die korrekte Diagnosestellung and für die Wahl der geeigneten Therapie, wenn eine Pankreasläsion bei einem Patienten mit einer vorangehenden Neoplasie auftritt.

ach, liver and spleen. However, lymphatic and haematogeneous dissemination are the most common, notably from carcinoma of the kidney and the lung. Less common are carcinomas from colon, thyroid, breast, skin, oesophagus, stomach, jejunum, gallbladder, bladder, endometrium or ovarium [2].

\begin{tabular}{ll}
\hline KARGER & @ 2010 S. Karger GmbH, Freiburg \\
Fax +497614520714 & Accessible online at: \\
Information@Karger.de & www.karger.com/brc \\
www.karger.com &
\end{tabular}

Dr. Stefano Amore Bonapasta 
We report a rare case of solitary pancreatic metastasis from lobular breast carcinoma. There have been only 11 cases described in the literature.

\section{Case Report}

In October 2000, a 51-year-old woman arrived at our clinic with a mass in her right breast, associated with skin dimpling, lymphoedema and palpable axillary lymph nodes. The tumour size was $3.5 \times 2 \mathrm{~cm}$. No distant metastases were revealed through a thorough evaluation including a bone gamma scan (even though the computed tomography (CT) scan revealed some lymphadenopathies). When histological examination was done, the mass was diagnosed as an invasive ductal carcinoma. The patient presented normal levels of CA 15-3 (3.1 U/ml) and other tumour markers.

She was treated with chemotherapy between October and December 2000 , with twice weekly intravenous injections of adriamycin (3 cycles, $75 \mathrm{mg} / \mathrm{mq}$ ) followed by 3 cycles of paclitaxel $(200 \mathrm{mg} / \mathrm{mq})$.

Subsequently, a mammography and a breast scintigraphy revealed complete remission of the mass after neo-adjuvant chemotherapy, even though lymphadenopathies persisted. For this reason, in January 2001, she underwent a superior-internal quadrantectomy and axillary dissection. Pathological examination showed two micro-focuses of infiltrating ductal carcinoma, grade II, oestrogen receptor (ER) (-), progesterone receptor (PgR) (-), HER2 (-), Ki-67 (20\%), p53 (20\%), Bcl-2 (+80\%), and node positive (15/16). She was once more treated with chemotherapy (epirubicin + docetaxel for 2 cycles, followed by 2 cycles of docetaxel, and 4 cycles of cyclophosphamide, methotrexate, 5 -fluorouracil (CMF) 1-8 days and regional radiotherapy) between February and June 2001.

The patient was in good clinical condition and the follow-up ensued negative until September 2002, when she presented with obstructive jaundice and epigastric pain. Total and direct bilirubin, $\gamma$-glutamyl transferase (GT), alkaline phosphatase (ALP) and transaminase levels were raised, and a distal bile duct obstruction was found by abdominal ultrasonography. On the magnetic resonance cholangiogram, a distal biliary obstruction suggestive of cholangiocarcinoma was detected, whereas the CT scan revealed a mass in the pancreas head, $2 \mathrm{~cm}$ in diameter, suggestive of primary pancreatic carcinoma (fig. 1). CA 19-9 and CA 15-3 levels were normal. In October 2002, she underwent a cephalic pancreaticoduodenectomy. The pathological exam showed infiltration of the pancreas head by a metastatic process of lobular breast carcinoma of $2 \mathrm{~cm}$ in diameter, with residues of ductal comedo type (fig. 2). The tumour was ER (+), PgR (+), HER2 (3+) (fig. 3). She had also 3 positive peripancreatic lymph nodes. After this operation, in November 2002, the patient underwent a CT scan for follow-up which did not reveal any other mass or metastatic sites. Also the tumour markers remained normal. Meanwhile chemotherapy was initiated with megestrol and then exemestrane.

The patient was asymptomatic until September 2003 when, because of the decline in general state, she underwent a CT scan, which revealed many lymphadenopathies that were incorporated in a mass of $5 \times 7 \mathrm{~cm}$ in diameter, with compression of the celiac tripode, aortic-mesenteric region, portal vein and renal artery. These growing lymphadenopaties also caused right hydronephrosis for homolateral ureteral obstruction. The progression of disease also caused a peritoneal carcinosis, diagnosed in May 2005. Then, she started cycles of chemotherapy with infusion of fluorouracil.

Nevertheless, in October 2005, the patient died.

\section{Discussion}

Breast cancer metastasises especially to bone, liver and lung. Pancreatic metastases are extremely rare and the incidence of

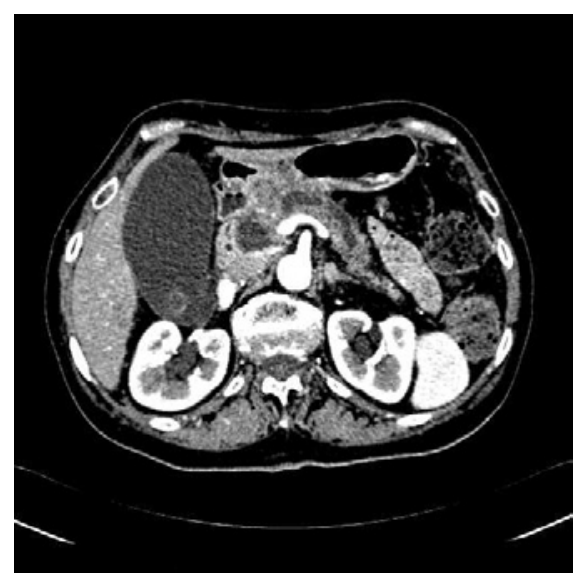

Fig. 2. Pathologic examination of the pancreas head tumour revealing an area of breast lobular carcinoma infiltrating the pancreatic tissue $(20 \times)$.
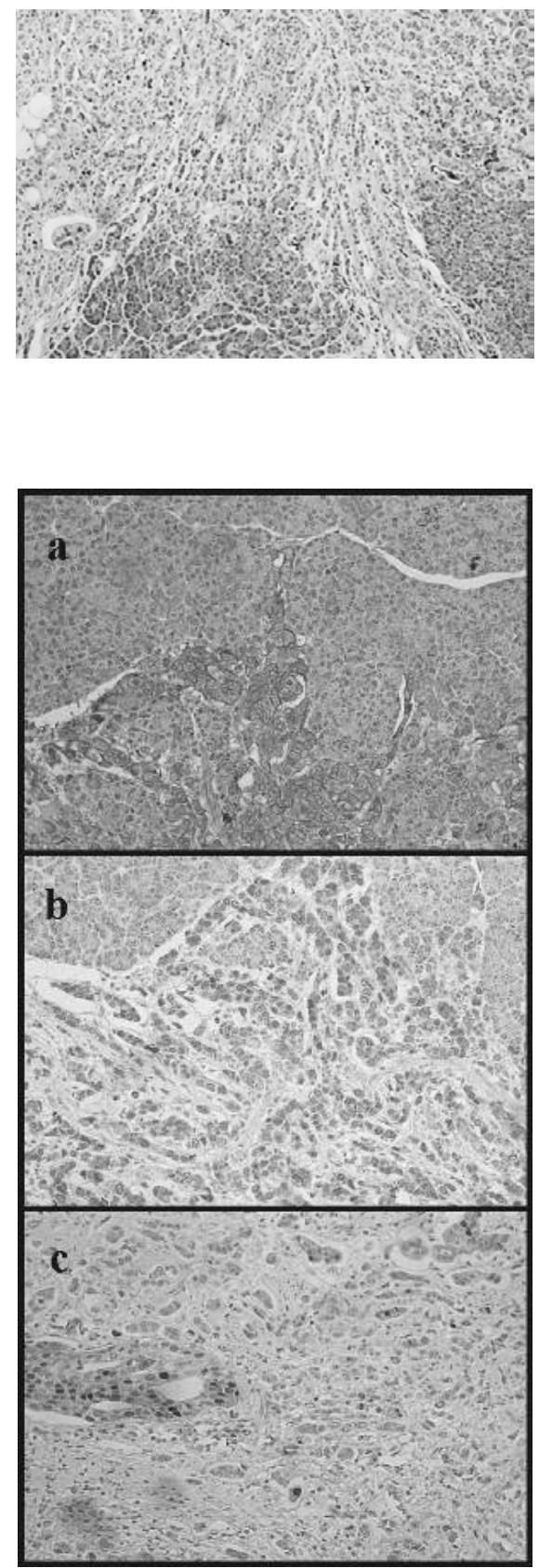

Fig. 3. Immunohistochemical staining of (a) HER2, (b) ER and (c) $P g R$ in the pancreatic head mass. 
pancreatic lesions like solitary metastasis sites for primary breast cancer is less than 3\% [3]. In the literature, we found 11 cases of solitary metastases to the pancreas [2, 4-11] and the dissemination to the pancreatic head is more common than to the pancreatic tail. Lobular carcinoma was demonstrated in 8 cases, signet-ring cells in one, comedo type in another and scirrhous type in another of the 11 treated cases. The diseasefree interval varies from 16 to 84 months (mean 43.3), and the interval of our case was 24 months without any symptoms [2, 4-11].

Ultrasonography, CT scan and magnetic resonance imaging (MRI) are used to diagnose pancreatic diseases, but it is often difficult to distinguish pancreatic metastasis from a primary pancreatic tumour [12]. The most important method for diagnosis is the pancreatic biopsy, but it does not always enable differentiation or is not at all possible. Since the metastasising tumours may closely mimic primary gastrointestinal cancers, the increase in the specific serum marker CA 15-3 can often help to make the differentiation possible. However, the increase of the CA 15-3 serum level is not always significant [13].

Previous studies showed that the prognosis of patients with metastatic disease to the pancreas is usually better than that for primary pancreatic carcinoma [4], but there are some conflicting opinions about the treatment of these patients. Surgery has been considered as a first-choice treatment in selected patients with pancreatic metastases [14], as well as the ones from breast cancer $[4,9]$. However, the procedures required for resection are characterised by noticeable mortality and significant morbidity [10]. Moreover, the option for resection should mainly be reserved for the case of metastatic processes limited to the pancreas and amenable to surgical resection [9].

In the reported case, the pancreatic lesion was $2 \mathrm{~cm}$ in diameter, and CT scan and magnetic resonance cholangiogram suggested a primary pancreatic carcinoma or a cholangiocar- cinoma. A biopsy could not be executed and only the operation revealed the histological nature of the lesion. The surgeon assumed that the lesion was a primary cancer of the pancreas or of the choledoco and decided to perform a cephalic pancreaticoduodenectomy. However, the positivity of axillary lymph nodes after quadrantectomy and the triple negativity indicated that the risk of metastatic spreading from the breast was high and suggested that the pancreatic mass could be a breast cancer repetition. In addition, we revealed, during all the clinical history, the negativity of CA 19-9 (the most important serum marker for primitive pancreatic cancer). Since an operation can reduce the immune response and the rehabilitation delays the start of chemotherapy, and considering the aggressive pattern of the breast tumour and the clinical history of the patient, we think that maybe a systemic therapy using gemcitabine (used for both pancreatic and breast cancer) could have provided better palliation and longer survival than surgical resection.

In conclusion, we believe that, when a pancreatic lesion develops in a patient with prior neoplasm, the hypothesis of a solitary metastasis to the pancreas should always be considered. The clinical history should be meticulously analysed and all suppositions have to be included in the diagnostic process. The decision for the treatment should require a team including an oncologist and a surgeon. The treatment should be individualised and the clinical decisions should be influenced by the site and the histologic type of the primary tumour, the interval from the first treatment to the time of occurrence of metastases, the clinical demands motivated by the metastatic process, the kind of necessary resection and the physical and mental status of the patient.

\section{Conflict of Interest}

The authors declare that there are no potential conflicts of interests.

\section{References}

1 Rumancik WM, Megibow AJ, Bosniak MA: Metastatic disease to the pancreas: evaluation by computed tomography. J Comput Assist Tomogr 1984;8: 829-834.

2 Tohnosu N, Narushima K, Sunouchi K, Saito T, Shimizu T, Tanaka H, Maruyama T, Watanabe Y, Kato T, Shimizu S, Uehara T, Ishii S: A case of breast cancer metastatic to the tail of the pancreas. Breast Cancer 2006;13:225-229.

3 Lee Y-TM: Breast carcinoma: pattern of metastasis at autopsy. J Surg Oncol 1983;23:175-180.

$\checkmark 4$ Pérez Ochoa A, Sáez Hernáez F, Cajigas Fernández C, Pérez de la Lastra L, Ondiviela Gracia R, García de Polavieja M: Pancreatic metastases from ductal and lobular carcinomas of the breast. Clin Transl Oncol 2007;9:603-605.
5 Mehta SA, Jagannath P, Krishnamurthy SC: Isolated pancreatic metastasis from locally controlled breast cancer: A case report. Indian J Cancer 1991; 28:48-50.

6 Mountney J, Maury AC, Jackson AM: Pancreatic metastases from breast cancer: an unusual cause of biliary obstruction. Eur J Surg Oncol 1997;23:574576.

7 Engel JJ, Trujillo Y, Spellberg M: Metastatic carcinoma of the breast: a cause of obstructive jaundice. Gastroenterology 1980;78:132-135.

8 Nomizu T, Katagata N, Matsuoka T, Suzuki S, Yabuta T, Watanabe F, Yamaki Y, Saito T, Tsuchiya A, Abe R: A case of breast cancer metastatic to the head of the pancreas. Breast Cancer 1999;6:131-134.

$\checkmark 9$ Crippa S, Bonardi C, Bovo G, Mussi C, Angelini C, Uggeri F: Pancreaticoduodenectomy for pancreatic metastases from breast carcinoma. JOP 2004;5: $377-383$.
10 Azzarelli A, Clemente C, Quagliuolo V: A case of pancreatoduodenectomy as resolutive treatment for a solitary metastasis of breast cancer. Tumori 1982;68:331-335.

11 Hiotis SP, Klimstra DS, Conlon KC, Brennan MF: Results after pancreatic resection for metastatic lesions. Ann Surg Oncol 2002;9:675-679.

12 Kidney DD, Cohen AJ, Butler J: Abdominal metastases of infiltrating lobular breast carcinoma: CT and fluoroscopic imaging findings. Abd Imaging 1997;22:156-159.

13 Duffy MJ: Serum tumor markers in breast cancer: are they of clinical value? Clin Chem 2006;52:345351.

14 Dar FS, Mukherjee S, Bhattacharya S: Surgery for secondary tumors of the pancreas. HPB (Oxford) 2008;10:498-500. 